\title{
A Pragmatic Analysis of Hedges from the Perspective of Politeness Principle
}

\author{
Jin Liu \\ School of Foreign Languages, Shanxi Normal University, Linfen, China
}

\begin{abstract}
In the process of daily interpersonal communication, hedges have a very wide and universal application. In the actual communication, hedges have their own unique pragmatic value in reducing the value of information in sentences, weakening the information in sentences and transferring the topic. This paper has adopted Politeness Principle proposed by Leech as the theoretical framework and aims to make an analysis of hedges used in the famous English literature Jane Eyre through the method of qualitative research. As a result, it is found there are four main functions as follows: maintaining a better communication environment, saving face and achieving the purpose of self-protection, making the expressions polite and euphemistic and making words more appropriate and acceptable.
\end{abstract}

Index Terms — hedges, politeness principle, pragmatic functions

\section{INTRODUCTION}

Language is a system of arbitrary vocal symbols used for human communication (Weidong Dai, 2013). In daily life, people prefer to use various words or phrases to express their feelings and ideas. These words and phrases include explicit and implicit ones. In other words, speakers can express their utterance meaning by using clear or fuzzy words or phrases. As to the conversational implication, people want to get a fuzzy conversation effect. They are willing to use some hedges to express their opinions, which require that the speakers and the hearers possess rich knowledge about hedges. The reason why people use hedges is that they want to make their utterances polite and euphemistic. The purpose of the paper arose from a concern that there were some researches carried out on hedges in novels, but it seems that there are few researches that have analyzed the pragmatic functions of hedges in Jane Eyre. Therefore, the goal of the present paper is to find out what are the pragmatic functions hedges perform in helping the story develop smoothly.

\section{LITERATURE REVIEW}

\section{A. Definition and Classification of Hedges}

Hedges refer to those words that deliberately make other words' meaning unclear. The term hedges first proposed by Lakoff (1975) in the thesis Hedges: a study in meaning criteria and the logic of fuzzy concepts. According to Lakoff, hedges refer to those words whose job is to make things fuzzier or a little fuzzier. Another linguist Yule (1972) also pays attention to the study of hedges. He regards hedges as conversational implication which can give the implicit meaning of utterances when people talk to each other. In terms of Hubler (1983), people use hedges to make their utterances more accessible so that hearers are willing to talk to them. In Mauranen (1997)'s view, hedges are the expressions which make the meaning of utterances uncertain. According to Brown and Levinson (2011), to a great degree, politeness is a main purpose that people want to arrive. Therefore, hedges are considered as polite strategies in human communication. The definitions above on hedges are different, but their essence is the same. Actually speaking, there is no fixed definition to hedges, because different linguistic scholars study it from various perspectives, such as discourse, semantics, pragmatics, and so on. What these linguists have studied on hedges has made great progress in linguistics.

There exist a large number of words which meet the standards and definition of hedges, such as certain adjectives, adverbs, impersonal phrases, modal verbs, and so on. L. A. Zadeh (1972) classifies hedges into two types in his thesis $A$ Fuzzy Set: Theoretic Interpretation of Linguistics Hedges, and it was the first time to decorate fuzzy words directly, such as very, more or less, much, essentially, slightly, and so on. Hedges can also be classified into two types according to the words they modify. One type is that they can just modify fuzzy words, such as very in very good and to some extent in satisfactory to some extent. The other one is that they can not only modify fuzzy words, but also modify exact words, just like the word about. So far, the most influential classification is worked out by E. F. Prince and his colleagues J. Frader and C. Bosk (1982) in terms of pragmatic functions. They hold that hedges can be classified into approximators and shields. To be more detail, approximators can be classified into adaptors and rounders. Shields can be divided into plausibility shields and attribution shields.

\section{B. Relevant Studies}

1. Researches on hedges abroad 
Researches on hedges may date back to the 1960s. Zadeh (1972) first proposes the fuzzy set theory. He analyzes English hedges such as very, much, more or less, highly and slightly from the point of view of semantics and logic. Lakoff (1975) is the first scholar who introduces the term hedge/hedging. He defines hedges as lexical units whose job is to make things fuzzier or less fuzzy. Prince, Frader and Bosk (1982) distinguish two types of hedges according to the speaker's commitment to the truth-value of a proposition. Their classification of hedges is widely employed by researches in the further studies. Brown and Levinson (2011) view hedges as a politeness strategy in verbal communication, in which they are used to avoid disagreement and express negative politeness, since hedges help reduce threats to one's face.

As for Zuck (1986) and Fraser (1990), they do a research on hedges with the specific discourses in the context. They aim to probe into the probable applications in their research findings and the pragmatic functions of hedges by analyzing the distribution characteristics.

Israel Scheffler (2004) holds that fuzziness is a universal feature of descriptive words, and it has a fundamental conflict with standard logic. He also suggests that there is something fundamental about the human brain, or that it comes from a deeply rooted line in nature.

2. Researches on hedges in China

In China, Tieping Wu (1979) is the first scholar who introduces a series of researches on linguistic vagueness. He does the first research on fuzzy linguistics, which marks the beginning of fuzzy linguistics in China in 1979. He defines fuzzy language as a language which has an unclear expression of epitaxial. In recent years, Ziran He (1985) has studied the application of hedges in daily communication. Zhi'an Chen and Yongping Ran (1995) have done a research about hedges and analyzed them in a pragmatic view. Na Dong (2003) has defined the hedges and made a classification of hedges. Guoli Zhuang and Hong Zhou (2009) have made a study on the correlation between the pragmatic functions of hedges and the Politeness Principle. Qiqiu Liang (2012) has made an exploration of hedges on the Internet in sociolinguistics. Haiyan Luo (2013) has made a study of the pragmatic functions of hedges in Friends. Jingjing Bi (2017) has made a pragmatic analysis of the hedges in How I Met Your Mother under Politeness Principle. Haiyun Gao (2018) has made a classification of hedges and discussed the pragmatic functions of the hedges used in daily communication.

\section{THEORETICAL FRAMEWORK: POLITENESS PRINCIPLE}

The six maxims of Politeness Principle proposed by Leech have made a great contribution to linguistic scholars' study of politeness as well as in human daily conversation. According to Leech, Politeness Principle is divided into six maxims, i.e. tact maxim, generosity maxim, approbation maxim, modesty maxim, agreement maxim and sympathy maxim (Leech, 1983). The following are Leech's six maxims of Politeness Principle.

(1) Tact Maxim, which refers to minimize costs to others and maximize benefits to others. In terms of maxim, Leech argued the speaker is supposed to try their best to minimize the hearers' costs or maximize their benefits.

(2) Generosity Maxim. The Generosity maxim includes sub-categories: minimizing benefits to self and maximizing costs to self.

(3) Approbation Maxim. This maxim consists of minimizing dispraise of others and maximizing praise of others. If the speakers intend to take the expensive actions, the approbation maxim will have a great effect.

(4) Modesty maxim. It is a maxim which covers two sub-branches: minimizing praise of self or maximizing dispraise of self. And it either requires the speakers to do the least compliment to self or to do the most description to themselves.

(5) Agreement maxim. There are two sub-maxims about this maxim: minimizing disagreement between self and other or maximizing agreement between self and other. It emphasizes if the speaker makes the declarative actions, he has to try his best to express his utterance meaning which should have the same or similar value with the hearer.

(6) Sympathy maxim. The sympathy maxim refers to minimize antipathy between self and other and maximize sympathy between self and other. According to this maxim, it requires that the speakers should make a sympathetic reaction towards others' complaint or unlucky sufferings. Because the sympathy maxim can function to strengthen the relationship between the speaker and the hearer.(Jingjing Bi, 2017: 13-14)

\section{A PRAGMATIC ANALYSIS ON HEDGES IN JANE EYRE}

\section{A. Maintaining a Better Communication Environment}

According to Tact Maxim, in a communication, people usually obey the principle in order to express the respect for others and try to avoid offending others, so they often use some euphemistic expressions. The speaker uses hedges deliberately to make the language ambiguous. This is to protect the hearer's face in some way so as to maintain a better communication environment.

For example, there's a clip in the novel that Jane Eyre left the school. After many years, she grew up. Because of the extremely difficult life, she had to make a living on advertising for a career as a tutor. Not long after that, Jane Eyre was hired by the housekeeper. Jane went far to the farm in a very cold weather and Mrs. Fairfax was very kind, full of carefulness.

(1) (Entering the building, Jane is warmly welcomed)

Maid: Miss Eyre, we’ve been expecting you. Will you come this way, please. 
Mrs. Fairfax: Ah! How do you do, my dear. I'm afraid you've had a tedious journey. You must be cold. Come and sit down by the fire.

In this conversation, Mrs. Fairfax was gentle and kind enough by using the hedges I'm afraid to protect Jane's face (the hearer) and avoid offending Jane. Although it was the first time that they greeted to each other, it still reflected the sincere concern of the speaker. It is polite and euphemistic. And this hedge has also played its important role here in maintaining a harmonious atmosphere between conversation participants.

Another conversation between Mr. Rochester and Jane shows the politeness and respect of the speaker. The speaker conveys his/her good temperament by using hedges in order to establish a good self-image. The dialogue as follows is a good example.

(2) "We must go in," said Mr. Rochester: "the weather changes. I could have sat with thee till morning, Jane."

"And so," thought I, "could I with you." I should have said so, perhaps, but a livid, vivid spark leap out of a cloud at which I was looking...

In this conversation, Mr. Rochester showed his sincere concern and carefulness to Jane. And Jane showed her shyness by thinking Could I with you. She used interrogative mood to express her feeling and it seemed that she doesn't want to be with Mr.

Rochester. But in fact, she was eager to stay with Mr. Rochester and willing to be accompanied by him. Here, Jane used this hedge to express her politeness and be euphemistic.

The third example happens between Mr. Lloyd and Jane. It shows the politeness and respect of the speaker to the hearer. The speaker conveys his/her good temperament by using hedges in order to establish a good self-image. The dialogue as follows is a good example.

(3) "If I had anywhere else to go, I should be glad to leave it, but I can never get away from Gateshead till I am a woman."

"Perhaps you may. Who knows? Have you any relations besides Mrs. Reed?"

"I think not, sir."

In this conversation, Mr. Lloyd showed his sincere concern and carefulness to Jane by using the hedge Perhaps. Mr. Lloyd hoped that Jane really had somewhere to go in order to get away from Gateshead. He used this hedge in order not to hurt Jane's little heart. And Jane showed her unwillingness of leaving for Mrs. Reed by using the hedge I think. It expresses her real feeling and it seems that she did not want to be with Mrs. Reed. And here, Mr. Lloyd got Jane' idea and there were no further questions about this topic. The hedges can not only express politeness and respect, but also maintain a better communication environment.

\section{B. Saving Face and Achieving the Purpose of Self-protection}

When speakers do not want to express their original intention or real idea clearly, they can use hedges to fuzzy boundaries or ranges so as to protect themselves and save their face.

When Mrs. Fairfax formally introduced Mr. Rochester to Jane, Mr. Rochester found that it was not the first time they met each other, so he wanted to learn more about Jane's birth, family, growing environment and so on. After asking if Jane could play the piano, he found that Jane answered in a cold way, which made Mr. Rochester feel that Jane was very independent and even unfriendly. Jane was Adele's tutor and taught her drawing. After drawing a few pictures, a conversation between Jane and Mr. Rochester came into being.

(4) Mr. Rochester: Did you copy them?

Jane Eyre: No, sir, they come out of my head.

Mr. Rochester: That head I see now on your shoulders?

Jane: Yes, sir.

Mr. Rochester: Has it other furniture of the same kind within?

Jane: I think it may have. Better I hope.

From the dialogue above, we can easily see that what made Mr. Rochester surprise was that even a humble, averagelooking governess can make a difference in painting. He was also skeptical and confuse about Jane's creative ideas, so he was right. The words were something cold and direct and even contained some disrespect for Jane. Jane's answer I think is not humble in showing her attitude and saving her face. The hedges used here protect the speakers' face and achieve self-protection successfully.

Another example for saving the speaker's face happened between Jane and the nurse. It was sad that Jane's best friend had been dead because of the serious illness. The detail is the following dialogue as it succeeds in achieving selfprotection.

"She is in Miss Temple's room," said the nurse.

"May I go up and speak to her?"

A From the dialogue above, we can easily see that Jane used the hedge May I...to achieve a fuzzy test to the hearer and manage to beg the cooperation of the nurse. The words are fuzzy and polite in order to establish a harmonious communication environment. Also, the fuzzy word may give the hearer an enough private room to make a choice. Only in this way could the speaker protect his/her face, achieve self-protection successfully and finally maintain a harmonious relationship in communication.

Example 6 happened between Mrs. Fairfax and Jane. People often use hedges to express their feelings and save their 
face in daily communication. The dialogue as follows is a good example.

(6) "I will go, if no better may be. But I don't like it. Shall you be there, Mrs. Fairfax?"

"No. I pleaded off, and he admitted my plea."

In this dialogue, Jane did not want to give trouble to Mr. Rochester, so she decided not to attend the party and discusses with Mrs. Fairfax. After discussion, Jane expressed her solution with a hedge may be. This hedge shows that Jane had no idea but to attend the party. For saving face and achieving self-protection, Jane added the hedge may be into her expression in order to get away from the embarrassment.

\section{Making the Expressions More Polite and Euphemistic}

According to Generosity Maxim, people usually obey the principle in order to make their expressions more euphemistic in a communication. In this way they can minimize benefits and maximize costs to themselves. The speaker uses hedges with some uncertain words to make the hearer comfortable and achieve a polite communication.

On a sunny morning, Jane Eyre taught drawing and she knew that Adele hoped to draw a portrait of Mr. Rochester because of the feeling of missing. Then Mr. Rochester knew that and played a joke to Jane on his appearance. Jane answered without hesitation.

(7) Jane Eyre: The beauty is of little consequence, something of that sort.

Mr. Rochester: Well, endure my surliness without being hurt.

In this conversation, Jane expressed her views directly on the beauty of the appearance. She thought that beauty was not important, or the like, using of that sort. Actually Jane expressed her view that appearance had never been important to her with the help of euphemisms. And Mr. Rochester also felt that the question might be offensive after listening to Jane's answer, so he also used the hedge well to release the awkward and disadvantageous atmosphere. These two euphemisms make the expression more appropriate. Here, the hedges are just like a lubricant, which is more conducive to the development of conversation.

Another example for making expressions more appropriate and euphemistic happened between Mrs. Lynn and the Dowager Ingram. It is sad that Jane's best friend was dead because of the serious illness. The detail is the following dialogue.

(8) "My dear boys, what are you thinking about?" exclaimed Mrs. Lynn.

"I cannot possibly countenance any such inconsistent proceeding," chimed in the Dowager Ingram.

"Indeed, mama, but you can and will," pronounced the haughty voice of Blanche, as she turned round on the pianostool...

In this conversation, Mrs. Lynn proposed a question directly in a sarcastic tone because she did not like Jane and aimed to incite anyone else against the arrival of Jane Eyre. But the Dowager Ingram held the view which was inconsistent with Mrs. Lynn because actually she did not want to offend Jane directly. So she expressed her views with the help of euphemisms by using the hedge possibly. Blanche also felt that the question might be offensive after listening to the Dowager Ingram's answer, so he also used the hedge indeed to release the awkward and disadvantageous atmosphere.

The ninth example happened between Mrs. Fairfax and Jane. People often use hedges to make their expressions appropriate and easy to accept in daily communication. In this dialogue, Jane used I suppose to express her respect for the hearer.

(9) "Mrs. Fairfax, I suppose?" said I.

"Yes, you are right. Do sit down."

In this conversation, Jane used the hedge I suppose to bring up a tentative conversation. By using this hedge, she avoided the embarrassment caused by mistaken identity effectively and deftly. The hedge indicated that Jane was very polite and respectful to Mrs. Fairfax. As a result, the using of this hedge built a harmonious atmosphere between both the speaker and the hearer. In a word, hedges can make the expressions more appropriate and euphemistic to maintain a comfortable communication environment.

\section{Making Words More Appropriate and Acceptable}

Hedges can reflect the speaker's attitude and viewpoint. It is still a plot of a conversation about Mr. Rochester's portrait, in which Mr. Rochester hoped that such questions did not harm Jane. But he knew more about Jane as she was self-respect, always pursued the freedom and equality. She was a precious girl with self-respect, self-reliance and selfimprovement. In this situation, the following dialogue occurs.

(10) Mr. Rochester: Do you believe that?

Jane Eyre: What, sir?

Mr. Rochester: That the shadows are as important as the light?

Jane Eyre: I believe that none of us is perfect. I believe none of us is without some fault to hide.

In this dialogue, Jane used two hedges I believe to show her attitude and opinion. It is very subjective and represents her understanding towards Mr. Rochester's question. But she added two I believe in her expressions to make the language more acceptable. It also reflects the valuable independent thought of Jane Eyre or even shapes a real Jane Eyre, a simple figure that thought "no one is perfect". The shadow of Mr. Rochester's marriage was removed. A good heart was hidden beneath his grim. In this way, the use of the hedges can make discourses more comprehensive and 
acceptable.

Example 11 is also one for saving the speaker's face and it happened between Jane and the nurse. It was sad that Jane's best friend had been dead because of the serious illness.

(11) "She is in Miss Temple's room," said the nurse.

"May I go up and speak to her?"

"Oh no, child! It is not likely; and now it is time for you to come in; you'll catch the fever if you stop out when the dew is falling."

In this conversation, the nurse used It is not likely to give Jane a fuzzy reply instead of a direct answer in order not to tell the truth that Helen had been dead and avoid hurting Jane's little heart. The pragmatic function of this hedge is making the expression more appropriate and acceptable, i.e. making another irrelevant reason that divert Jane's attention successfully and make a more appropriate reply that Jane is easy to accept.

\section{CONCLUSION}

\section{A. Main Findings}

Hedges play an important role in human communication as a kind of fuzzy language. It is a common but essential phenomenon which attracts many linguists to pay more attention to. This paper analyzes hedges in the famous novel Jane Eyre in terms of pragmatics and describes how these hedges are used to fulfill the six maxims of politeness principle. Just like what is analyzed in the paper, hedges are able to maintain a better communication environment, save face and achieve the purpose of self-protection, make the expressions polite and euphemistic and make words more appropriate and acceptable, so that the speaker and the hearer will be willing to communicate with each other, and the conversation can be smooth.

\section{B. Implications}

Through analyzing the dialogues in Jane Eyre in detail, we can get the following implications. At first, hedges play an important role in our daily life. Both speakers and hearers can use different hedges to meet their communicative intention. In this way, the context where hedges are used is rather crucial. Speakers should pay more attention to linguistic environment, and meanwhile hearers should also understand what speakers' conversational implications are. What's more, when people use hedges in their utterances, they intend to imply something or make some information implicit and uncertain. Different kinds of hedges can produce different conversational effects and intentions in different contexts. The functions of hedges are to make the conversation smooth and successful. In conclusion, based on Politeness Principle, the paper analyzes how to use hedges to show the six maxims of Politeness Principle. The appropriate usage of hedges can produce a better communicative effect between speakers and hearers. Studying these hedges roundly and deeply not only has a great effect on the study of theories of semantics and pragmatics, but also has practical significance for the ways of using hedges appropriately.

\section{Limitations and Suggestions for Further Researches}

Although this paper has done many studies on the pragmatic functions of hedges in Jane Eyre, there are still some limitations. First of all, this paper is only the analysis of some dialogues in Jane Eyre and the examples are limited. Secondly, because of the author's limited knowledge, the analysis may be subjective and insufficient. Thirdly, the author does not have a deep understanding of the theoretical framework, which may lead to some mistakes in the analysis.

On account of the limitations of this paper, there are some suggestions for further researches. First of all, we should do lots of reviews on the previous studies in order to have an all-around knowledge of the related subjects, so that we could make a more accurate and adequate analysis. Secondly, we are supposed to pay attention to hedges in various types of material in order to have a deep understanding of pragmatic functions of hedges. Finally, we should actively explore the correlation between hedges and other achievements in linguistics in order to put relevant theories into practice.

\section{ACKNOWLEDGMENTS}

I would like to express my gratitude to all those who helped me during the writing of this paper.

To begin with, I would like to extend my deepest gratitude to my academic advisor, Junying Kang, who provided me guidance, support and encouragement in my research. She has walked me through all the stages of the writing of this paper. Being a student of Junying Kang would be one of the greatest occurrences in my lifetime.

Secondly, I would like to express my heartfelt gratitude to the professors and teachers in School of Foreign Languages, Shanxi Normal University.

In addition, my thanks would go to my beloved family for their loving considerations and great confidence in me all through the year. I also owe my sincere gratitude to my friends and classmates who gave me their help and time in listening to me and helping me work out my problems during the difficult course of the paper.

Last but not least, my sincere thanks are given to the authors whose works and papers benefit me a lot. 


\section{REFERENCES}

[1] Brown, P. \& S. C. Levinson. (2011). Politeness: Some Universals in Language Usage. Cambridge: Cambridge University Press.

[2] Fraser, B. (1990). Perspectives on politeness. Journal of Pragmatics, 4, 219-236.

[3] Guoli Zhuang and Hong Zhou. (2009). Hedges and Politeness Principle. Foreign Languages in China, 2, 43-47.

[4] Haiyan Luo. (2013). A Study of Hedges in Friends from the Perspective of Politeness Principle. Nanjing: Nanjing Normal University.

[5] Haiyun Gao. (2018). The Classification of Hedges and Its Pragmatical Functions in Vocal communications. West Leather, 5, 915.

[6] Hubler, A. (1983). Understatements and Hedges in English Language. Oxford: Oxford University Press.

[7] Jinging Bi. (2017). A Pragmatic Analysis of Hedges in How I Met Your Mother from the Perspective of Politeness Principle. Shenyang: Liaoning University.

[8] Lakoff, George. (1975). Hedges: a study in meaning criteria and the logic of fuzzy concepts. Journal of Philosophical Logic, 2 , 195-213.

[9] Leech, G. N. (1983). Principles of Pragmatics. London: Longman.

[10] Mauranen, A. (1997). Hedging in Language Revisers' Hands. Oxford: Oxford University Press.

[11] Na Dong. (2003). The Definition and Classification of Hedges. Journal Beijing Second Foreign Language Institute, 4, $28-34$.

[12] Prince, E. F. Frader, J. \& C. Bosk. (1982). On hedging in physician discourse. In Di Pietro, R. J. (ed.). Linguistics and Professions. Norwood: Ablex, 83-97.

[13] Qiqiu Liang. (2012). A Study on Net speak Vagueness from the Perspective of Sociolinguistics. Shanghai: Shanghai International Studies University.

[14] Scheffler, I. (2004). Beyond the Letter. A Philosophical Inquiry into Ambiguity, Vagueness and Metaphor in Language. London: Routledge and Kegan Paul.

[15] Tieping Wu. (1979). A preliminary Study on Fuzzy Language. Journal of Foreign Languages, 4, 39-44.

[16] Weidong Dai. (2013). A New Concise Course in Linguistics for Students of English. Shanghai: Shanghai Foreign Language Education Press.

[17] Yule, H. P. (1972). Conversational Text Editor for a Laboratory Minicomputer. Analytical Chemistry, 24, 1-430.

[18] Zadeh, L. A. (1972). A Fuzzy-set-theoretic Interpretation of Linguistic Hedges. Journal of Cybernetics, 3, 4-34.

[19] Zhian Chen and Yongping Ran. (1995). Hedges and Its Pragmatical Analysis. Journal of Sichuan International Studies University, 1, 18-24.

[20] Ziran He. (1985). Fuzzy Constrains and Vocal Communication. Journal of Foreign Languages, 5, 27-31.

[21] Zuck, J. G. and L. V. Zuck. (1986). Hedging in news Writing. In A. M. Cornu, Vanparijs, J. Delahaye, M. \& L. Baten. (eds.) Beads or Bracelets? How do we Approach LSP?. Oxford: Oxford University Press, 172-180.

Jin Liu was born in Shanxi Province, China in 1996. She is studying for her Master's Degree in Foreign Linguistics and Applied Linguistics in Shanxi Normal University, China in 2020. Her research interests include pragmatics, critical discourse analysis and translation. 